\title{
Biliary cirrhosis caused by Campula spp. in a dolphin and four porpoises
}

\author{
J. R. Jaber ${ }^{1, *}{ }^{,}$J. Pérez ${ }^{2}$, D. Rotstein ${ }^{3}$, R. Zafraa ${ }^{1}$, P. Herráez ${ }^{1}$, C. Carrascosa ${ }^{1}$, \\ A. Fernández ${ }^{1}$ \\ ${ }^{1}$ Institute of Animal Health, Veterinary Faculty, University of Las Palmas de Gran Canaria, \\ Trasmontaña s/n 35416 Arucas (Gran Canaria), Spain \\ ${ }^{2}$ Department of Comparative Pathology, Veterinary Faculty, University of Córdoba, Edificio de Sanidad Animal, \\ Campus de Rabanales, 14014 Córdoba, Spain \\ ${ }^{3}$ Private Consulting Pathologist, College Park, Maryland 20740, USA
}

\begin{abstract}
Biliary cirrhosis produced by Campula spp. is described in 1 striped dolphin Stenella coeruleoalba and 4 harbour porpoises Phocoena phocoena. The hepatic lesions consisted of severe proliferation of fibrous connective tissue with loss of the lobular pattern, nodular regeneration of the hepatic tissue, bile duct hyperplasia and severe inflammatory infiltrate composed of eosinophils, macrophages, lymphocytes and plasma cells. These lesions were associated with severe infestation by Campula spp. Although inflammatory and degenerative hepatic lesions are frequently found in stranded dolphins, biliary cirrhosis has not been previously reported in cetaceans. Massive infestation by these parasites should be included as a cause of hepatic failure resulting in stranding of marine mammals.
\end{abstract}

KEY WORDS: Cetacean $\cdot$ Stenella coeruleoalba $\cdot$ Phocoena phocoena $\cdot$ Hepatic lesions $\cdot$ Biliary cirrhosis $\cdot$ Trematode

\section{INTRODUCTION}

Interest in parasitic diseases of marine mammals has increased greatly during the last few years because they have accounted for an important portion of the pathological changes found in these animals (Dailey \& Ridgway 1976). One of the most frequent parasitic infestations observed in the digestive system of cetaceans is produced by Campula spp., trematodes that primarily inhabit the bile and pancreatic ducts of cetaceans (Zam et al. 1971). A high prevalence of these worms in different species of cetaceans has been reported (Zam et al. 1971, Sweeney \& Ridgway 1975, Dailey \& Stroud 1978, Jaber et al. 2004), producing extensive irritation of the ducts, fibrosis in the portal areas, biliary hyperplasia (Dailey \& Stroud 1978) and inflammatory infil- tration composed mainly of lymphocytes, plasma cells and eosinophils (Migaki et al. 1979).

In humans, chronic obstruction of the intrahepatic biliary duct may result in primary biliary cirrhosis (PBC; Speranzini et al. 1988, Crawford 1999), characterised by granulomatous inflammation and destruction of medium-sized intrahepatic biliary ducts, portal inflammation and subsequent fibrosis, resulting in cirrhosis and hepatic insufficiency (Gershwin et al. 2000). The hepatic dysfunction produced by this disease can result in a metabolic disorder of the central nervous system that is termed hepatic encephalopathy (Crawford 1999). In terrestrial mammals, biliary cirrhosis has been experimentally induced by surgery in dogs (Koblik et al. 1995) or by antifungal drugs in rats (Somchit et al. 2004), and has been associated in cattle with parasites (Vítovec 1974) or a 
mass in the biliary tract (Shimada et al. 1998). However, to date, this disease has not been described in marine mammals. The aim of this paper was to study the pathological and immunohistochemical findings associated with severe infestation by Campula spp. in 2 species of cetaceans stranded in different locations.

\section{MATERIALS AND METHODS}

A total of 5 animals were included in this study: 4 subadult harbour porpoises Phocoena phocoena (3 females, 1 male) stranded on the eastern coast of the USA and 1 mature male striped dolphin Stenella coeruleoalba stranded on the shore of Fuerteventura, Canary Islands, Spain. The latter showed hypothermia, disorientation and weakness. A full post mortem examination was carried out for all 5 animals. After opening the abdominal cavity, an increase in the abdominal fluid and moderate yellowish colouration of the serosal membranes were observed. Grossly, the liver was normal in size, but moderately hard in consistency. The liver of the striped dolphin showed the presence of numerous hard and whitish nodules ranging from 2 to $3 \mathrm{~cm}$ in diameter, affecting approximately half of the organ, and associated with marked dilatation of the hepatic ducts. In the other animals, these nodules affected one third of the organ. The common hepatic duct contained numerous adult trematodes, causing a partial obstruction of this duct. Samples from the central nervous system, lung, heart, liver, spleen, forestomach, fundic stomach, pyloric stomach, pancreas, adrenal gland, intestine, and prescapular, mediastinal and mesenteric lymph nodes were collected and fixed in $10 \%$ neutral buffered formalin. Formalin-fixed tissues were routinely processed, embedded in paraffin wax, sectioned at $5 \mu \mathrm{m}$, and stained with haematoxylin and eosin (H\&E) for histological examination.

For the ultrastructural study, liver tissue samples from the striped dolphin initially fixed in formalin were post-fixed in osmium tetroxide ( $\mathrm{pH}$ 7.4) and embedded in epoxy resin. Semi-thin sections were cut and stained with toluidine blue for light microscopical examination. Ultrathin sections were cut from selected blocks, stained with lead citrate and uranyl acetate and examined using a Philips CM-10 transmission electron microscope. To study parasites found in the liver, samples were processed, goldsputtered, and examined using a Jeol JSM 6300 scanning electron microscope.
Selected sections were stained by an immunoperoxidase test for Morbillivirus antigen (Kennedy et al. 1991). The avidin-biotin-peroxidase method described elsewhere (Pérez et al. 2001, Jaber et al. 2013) was used to further characterise the inflammatory infiltrate. Details of the optimal antigen retrieval methods and dilutions of the specific primary antibodies are given in Table 1. Primary antibodies against CD3, lysozyme, MHC class II, S-100 protein and immunoglobin (IgG) have been shown to crossreact with cetacean tissues (Jaber et al. 2003). Crossreactivity between the primary antibodies anti-rat Foxp3 and anti-human iNOS in cetacean tissues was evaluated in the present study. Tissue sections in which the specific primary antibodies were substituted with PBS, rabbit or mouse non-immune sera were used as negative controls. Dolphin, human, bovine and mouse lymph node tissue sections were used as positive controls. Immunolabelled tissue sections were evaluated with a photomicroscope, and the density of immunolabelled cells in affected areas was scored by 2 pathologists in 10 fields of $0.2 \mathrm{~mm}^{2}$ as follows: - , negative; $\pm /-, 0$ to $5 ;+, 6$ to $15 ;++, 16$ to 30 ; ,$+++>30$ cells per field.

\section{RESULTS AND DISCUSSION}

Histological examination revealed that the biliary ducts contained an elevated number of adult parasites and eggs. Morphologic features were consistent with Campula spp. (Zam et al. 1971, Dailey \& Stroud 1978), characterised by the single pair of anterior diverticula of the intestinal caeca and the lobed testes. Scanning electron microscopy revealed a tegument that was covered with large and scale-like

Table 1. Primary antibodies used in this study. pAb: polyclonal antibody; mAb: monoclonal antibody. Treatments were as follows; Pronase: $0.01 \%$ pronase (Sigma Chemical) for $10 \mathrm{~min}$ at room temperature; Microwave: $0.01 \%$ citric acid in microwave at $100^{\circ} \mathrm{C}$ for $7 \mathrm{~min}$; Autoclave: $0.01 \%$ citric acid in autoclave at $121^{\circ} \mathrm{C}$ for $10 \mathrm{~min}$

\begin{tabular}{|c|c|c|c|c|}
\hline Antibody & Origin & Treatment & Dilution & Manufacturer \\
\hline CD3 (pAb) & Human & Pronase & $1: 200$ & Dako \\
\hline $\begin{array}{l}\text { Lysozyme } \\
\text { (pAb) }\end{array}$ & Human & Pronase & $1: 100$ & Dako \\
\hline S-100 (pAb) & Bovine & None & $1: 200$ & Dako \\
\hline iNOS (pAb) & Mouse & Pronase & $1: 100$ & Neomarkers \\
\hline $\operatorname{IgG}(\mathrm{pAb})$ & Human & Pronase & $1: 1000$ & Dako \\
\hline $\begin{array}{l}\text { MHC class II } \\
(\mathrm{mAb})\end{array}$ & Human & Microwave & $1: 50$ & Dako \\
\hline Foxp3 (mAb) & Mouse & Autoclave & $1: 100$ & eBioscience \\
\hline
\end{tabular}




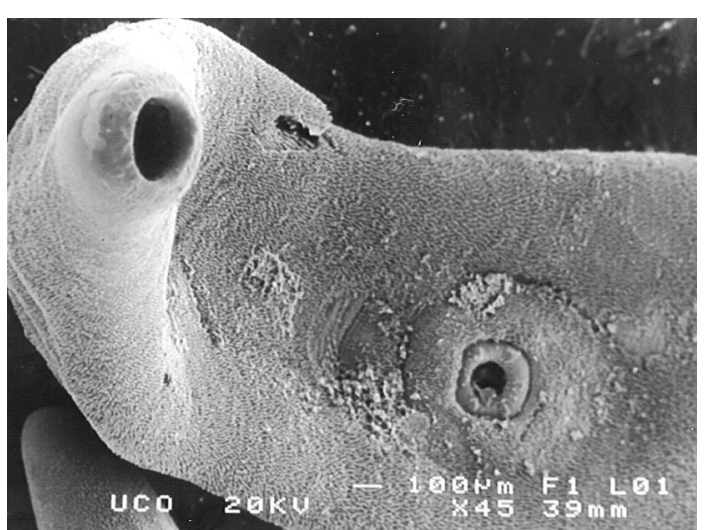

Fig. 1. Campula sp. Detail of the suckers of the parasite and its tegument with large and scale-like spines (scanning electron microscopy) $\times 45$

spines and the presence of 2 suckers, one observed ventrally (also called the acetabulum) and the other surrounding the mouth or anterior sucker (Fig. 1).

The presence of parasites in the bile ducts induced epithelial cell erosion, bile duct hyperplasia, portal fibrosis and severe inflammatory infiltrate (Fig. 2). Rupturing of the affected biliary ducts resulted in the presence of parasites and their eggs in the stroma, which was surrounded by eosinophils, lysozymepositive macrophages and multinucleate giant cells, and peripherally by numerous $\mathrm{CD}^{+} \mathrm{T}$ lymphocytes and $\mathrm{IgG}^{+}$plasma cells leading to granulomata formation (Table 2). Severe bridging fibrosis that extended from one portal tract to another was observed (Fig. 2). Within the fibrotic regions, there was some nodular regeneration of the hepatic tissue resulting in disorganisation of the hepatic architecture and neovascularisation, bile duct proliferation and infiltration of mononuclear cells composed of lysozyme-positive macrophages, $\mathrm{CD}^{+}$lymphocytes (Fig. 3) and $\mathrm{IgG}^{+}$plasma cells within the fibrotic tissue. Around these portal areas, there was an abundant inflammatory infiltrate composed of $\mathrm{IgG}^{+}$ plasma cells and $\mathrm{CD}^{+}$lymphocytes, which were predominantly organised in lymphoid follicles, with prominent germinal centres and interfollicular diffuse lymphoid tissue.

Occasional cells with large cytoplasm identified as macrophages showed cytoplasmic immunostaining for iNOS. The low numbers of macrophages expressing iNOS in the inflammatory infiltrate of the present study agree with the low iNOS expression in chronic cholangitis caused by Fasciola hepatica in goats and sheep (authors' unpubl. results). The Foxp3 antibody showed nuclear and cytoplasmic immunoreactivity in some lymphocytes located in the paracortical areas of dolphin lymph nodes and also in a few lymphocytes in the hepatic inflammatory infiltrates, mainly in diffuse lymphoid infiltrate closely related to bile ducts where 5 to $8 \%$ of lymphocytes were foxp $3^{+}$(Fig. 4). In parasitic diseases of domestic animals, such as Psoroptes ovis in sheep, Foxp3 $3^{+} \mathrm{T}$ lymphocytes are recruited to the skin lesions (McNeilly et al. 2010). In contrast, no Foxp3 ${ }^{+}$cells were found in hepatic lesions caused by Schistosoma mansoni in mice (Dewals et al. 2010), and reduction of this cell type in chronic colonic granulomas compared to acute lesions was observed in mice infected with $S$. mansoni (Turner et al. 2011). In chronic hepatic lesions caused by $F$. hepatica in goats, a marked reduction of Foxp3+ cells was found (authors' unpubl. data). This is in agreement with the occasional Foxp3 ${ }^{+}$cells found in the hepatic inflammatory infiltrates of the cetaceans in the present study and also with recent studies reporting that helminths such as $S$. mansoni and Heligmosomoides polygyrus led to a reduced

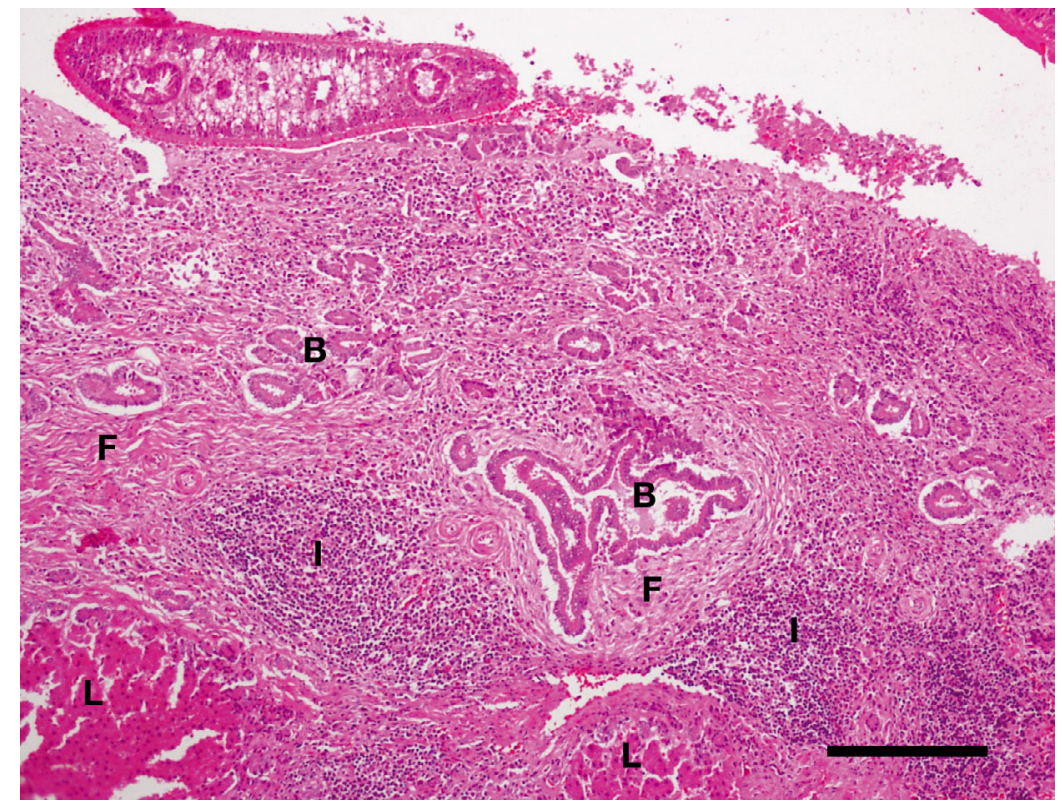

Fig. 2. Campula sp. infecting Phocoena phocoena. Presence of the parasite in a liver bile duct (B) showing severe portal fibrosis (F) and inflammatory infiltration (I) in portal spaces and hepatic parenchyma (L), resulting in loss of the he patic lobular pattern (H\&E). Scale bar $=100 \mu \mathrm{m}$ 
Table 2. Phocoena phocoena and Stenella coeruleoalba. Distribution of immunolabelled cells $(-: 0 ;+/-: 0-5 ;+: 5-15 ;++: 15-30 ;+++:>30$ cells per $0.2 \mathrm{~mm}^{2}$ ) with the stated antibodies in the lymphonodular inflammatory infiltrates of the liver. LYSOZ: lysozyme

\begin{tabular}{|lcccccccc|}
\hline Case no. & CD3 & LYSOZ & S-100 & iNOS & IgG & $\begin{array}{c}\text { MHC } \\
\text { class II }\end{array}$ & Foxp3 \\
\hline Harbour porpoise & & & & & & & \\
IFAW11-054Pp & +++ & ++ & ++ & - & +++ & + & + \\
IFAW11-088Pp & ++ F & $+/-$ & + & - & + & + & - \\
IFAW11-039Pp & +++ & + & + & $+/-$ & $++/+++$ & + & + \\
IFAW11-009Pp & +++ & $+/-$ & + & $+/-$ & + & $+/-$ & - \\
Striped dolphin & & & & & & & \\
$61 / 00$ & +++ & - & - & $+/-$ & ++ & $+/-$ & $+/-$ \\
\hline
\end{tabular}

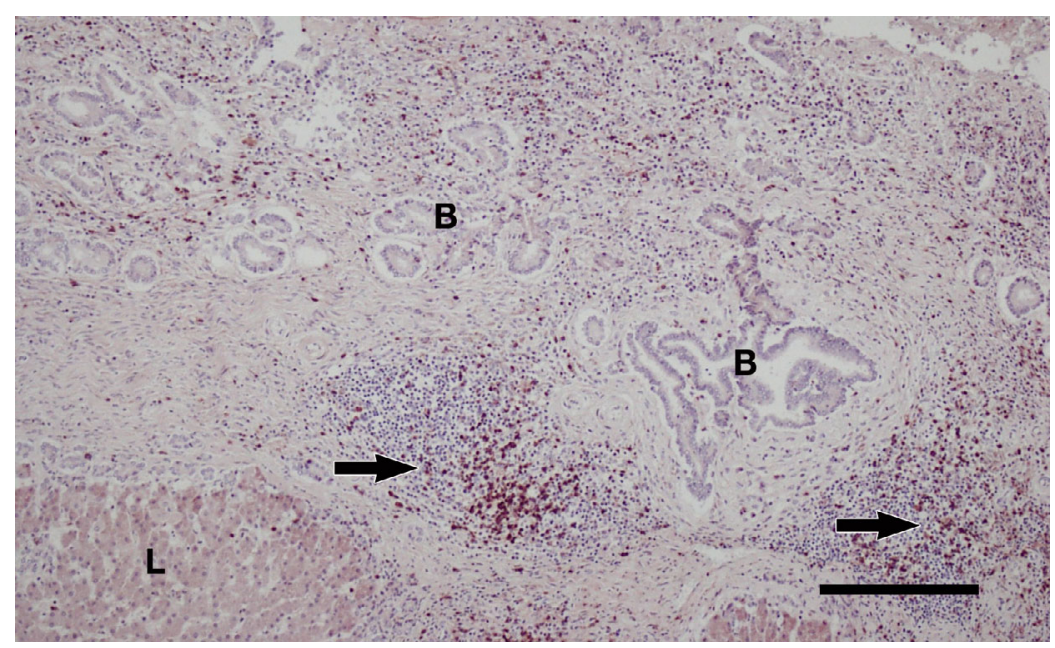

Fig. 3. Phocoena phocoena. Bile duct proliferation (B) and infiltration of mononuclear cells composed mainly of $\mathrm{CD}^{+}$lymphocytes (arrows) within the fibrotic tissue. L: liver. (avidin-biotin-peroxidase method, Mayer's haema toxylin counterstain). Scale bar $=100 \mu \mathrm{m}$

In the striped dolphin, some hepatocytes contained cytoplasmic hyaline inclusions, which were round to oval in shape, moderately eosinophilic and on occasion caused peripheral displacement of the nucleus. In these inclusions, a central or eccentric densely staining core was frequently apparent. During stranding, thoracic and abdominal vasculature compression compromises blood flow, leading to acute to subacute liver congestion and subsequent hepatocellular hypoxia. These hepatocytes then develop hyaline inclusions, which are similar to those seen in humans with congestive heart failure (Ponsold 1961). This finding suggests that this morphological change would be reversible, as in humans (Jaber et al. 2004)

In the central nervous system of the striped dolphin, numerous cell bodies of the neurons were shrunken and the cytoplasm stained lightly eosinophilic, whereas the nucleus of the neurons was reduced in size, and the nucleolus was not detectable. Accumulations of glial cells were found surrounding neuronal cell bodies and vessels. Diffuse vacuolation, particularly the white matter, was observed. This vacuolation showed a well defined pattern following a number of myelinated tracts in central nervous system white matter, in isolated fibres crossing grey matter in the

expansion and maintenance of Foxp3 Treg cells (Redpath et al. 2013).

The lymphoproliferative nodules were associated with the parasitic cholangitis and were similar to those found in the cortex of control lymph nodes, including the presence of $\mathrm{S} 100^{+}$and $\mathrm{MHC}$ class $\mathrm{II}^{+}$dendritic-like cells in lymphoid follicles and interfollicular areas. Similar cellular distribution has been reported in goats (Pérez et al. 1999) parasitised by Fasciola hepatica and in pigs parasitised by Ascaris suum (Pérez et al. 2001). The organisation of these lymphonodular inflammatory infiltrates may enhance antigen presentation and the local humoral and cellular immune responses against parasite or egg antigens. In addition, the high number of $\mathrm{IgG}^{+}$plasma cells indicates a strong local humoral response against this parasite. brain stem, and along grey and white matter borders in the cerebrum and spinal cord. These histological findings were suggestive of hepatic encephalopathy, which is a complication that develops in a small percentage of human patients with chronic liver disease (Durán-Ferreras et al. 2011). However, in the above mentioned case, it is difficult to distinguish whether the cause of the vacuolation was provoked by this process or related to agonal hypoxia.

The test for Morbillivirus antigens was negative in all of the selected sections studied. Histopathological examination of the remaining organs was not remarkable.

In humans, PBC is an organ-specific autoimmune disease that predominantly affects women and is characterised by chronic progressive destruction of 


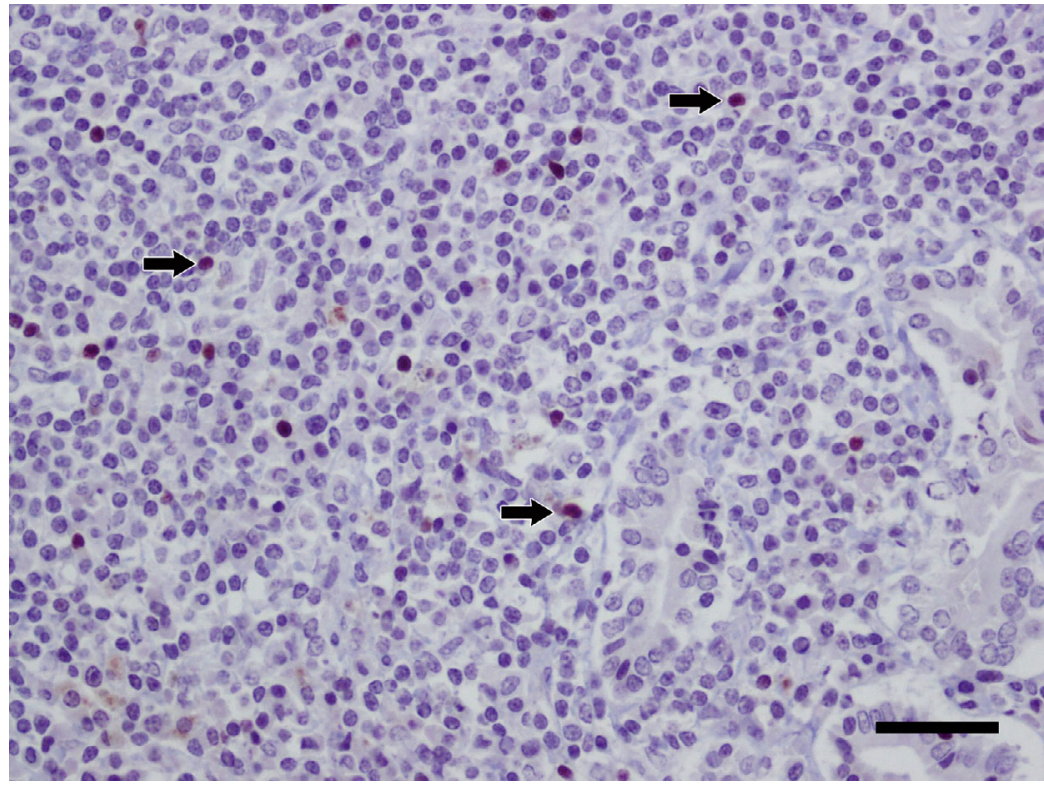

Fig. 4. Stenella coeruleoalba. Foxp3 antibody showing nuclear and cytoplasmic immunoreactivity in a few lymphocytes (arrows) located in the hepatic inflammatory infiltrates in the liver (avidin-biotin-peroxidase method, Mayer's haematoxylin counterstain). Scale bar $=50 \mu \mathrm{m}$ cetaceans. While these lesions have been well documented in ruminants with fascioliasis and in humans with biliary trematodiasis, little has research has been conducted with the spectrum of lesions reported in cetaceans. It seems that the massive infestation by this parasite should be considered a differential diagnosis of hepatic failure resulting in stranding of marine mammals.

Acknowledgements. We are indebted to Marisa Mohamad and Jamal Jaber for their constructive comments. We also thank Misty Niemeyer, Marine Mammal Rescue and Research, International Fund for Animal Welfare, Massachusetts (USA), for providing samples. We acknowledge the Spanish Ministry of Science and Innovation (CGL 2009/12663, CGL 2009/08125), the Canary Islands Science and Technology Program (SolSub C200801000288) and the Juan de la Cierva Program. small intrahepatic bile ducts with portal inflammation and ultimately fibrosis (Gershwin et al. 2000). Biliary cirrhosis observed in the dolphins in the present study was associated with parasites and their eggs in the stroma of portal spaces. A parasitic origin of PBC has been reported in cows parasitised by Fasciola hepatica (Vítovec 1974, Pérez et al. 1999). This trematode has frequently been found in the liver and pancreas of cetaceans (Migaki et al. 1979, Jaber et al. 2004). Light infestation may be asymptomatic, but heavy infestations may cause changes similar to those observed in the present study, in which major severity of the lesions was observed when parasite eggs were found in the stroma of portal spaces, causing severe granulomatous lesions with destruction of the biliary ducts, similar to that described in humans (Crawford 1999, Gershwin et al. 2000). Thus, the histopathological features closely resemble those reported in humans (Crawford 1999), but the lymphocytic infiltrate in granulomatous lesions associated with parasite eggs was more prominent in this dolphin. Biliary cirrhosis caused by Fasciola spp. in ruminants (Vítovec 1974) and experimentally induced in dogs (Koblik et al. 1995) also showed similar histopathological features to those observed in our case.

To date, there have been no reports of primary biliary cirrhosis associated with Campula spp. in

\section{LITERATURE CITED}

Crawford JM (1999) The liver and biliary system. In: Cotran RS, Kumar V, Collins T (eds) Robbins Pathological basis of disease. W. B. Saunders, Philadelphia, PA, p 881-940

> Dailey MD, Ridgway SH (1976) A trematode from the round window of an Atlantic bottlenosed dolphin's ear. J Wildl Dis 12:45-47

> Dailey MD, Stroud RK (1978) Parasites and associated pathology observed in cetaceans stranded along the Oregon coast. J Wildl Dis 14:503-511

> Dewals B, Hoving JC, Horsnell WG, Brombacher F (2010) Control of Schistosoma mansoni egg-induced inflammation by IL-4-responsive CD4 (+) CD25(-) CD103(+) Foxp3(-) cells is IL-10-dependent. Eur J Immunol 40: 2837-2847

> Durán-Ferreras E, Díaz-Narváez F, Raffo-Márquez M (2011) Chronic hepatic encephalopathy in a patient with primary biliary cirrhosis. Gastroenterol Hepatol 34:401-405

- Gershwin ME, Ansari AA, Mackay IR, Nakanuma Y, Nishio A, Rowley MJ, Coppel RL (2000) Primary biliary cirrhosis: an orchestrated immune response against epithelial cells. Immunol Rev 174:210-225

> Jaber JR, Fernández A, Herráez P, Espinosa de los Monteros A and others (2003) Cross-reactivity of human and bovine antibodies in striped dolphin paraffin waxembedded tissues. Vet Immunol Immunopathol 96:65-72

Jaber JR, Pérez J, Arbelo M, Hidalgo M, Gómez-Villamandos JC, van Den Ingh T, Fernández A (2004) Histopathogical and ultrastructural hepatic changes in cetaceans stranded in the Canary Islands. Vet Pathol 41: 147-153

Jaber JR, Pérez J, Carrascosa C, Carballo M, Fernández A (2013) Non-specific reactive hepatitis in dolphins 
stranded in the Canary Islands. J Appl Anim Res doi: 10.1080/09712119.2013.787363

Kennedy S, Smyth JA, Cush PF, McAliskey M, McCullough S, Rima BK (1991) Histopathologic and immunocytochemical studies of distemper in harbor porpoises. Vet Pathol 28:1-7

Koblik PD, Hornof W, Yen CK, Fisher PE, Komtebedde J (1995) Use of technetium-99m sulfur colloid to evaluate changes in reticuloendothelial function in dogs with experimentally induced chronic biliary cirrhosis and portosystemic shunting. Am J Vet Res 56:688-693

McNeilly TN, McIntyre J, Frew D, Griffiths DJ, Wattegedera SR, van den Broek A, Huntley JF (2010) Infestation of sheep with Psoroptes ovis, the sheep scab mite, results in recruitment of Foxp3 (+) T cells into the dermis. Parasite Immunol 32:361-369

Migaki G, Lagios M, Herald ES, Dempster RP (1979) Hepatic trematodiasis in a Ganges River dolphin. J Am Vet Med Assoc 175:926-928

> Pérez J, Martín de las Mulas J, Carrasco L, Gutierrez PN, Martínez-Cruz MS, Martínez-Moreno A (1999) Pathological and immunohistological study of the liver and hepatic lymph nodes in goats infected with one or more doses of Fasciola hepatica. J Comp Pathol 120: $199-210$

Pérez J, García PM, Mozos E, Bautista MJ, Carrasco L (2001) Immunohistochemical characterization of hepatic lesions associated with migrating larvae of Ascaris suum in pigs. J Comp Pathol 124:200-206

Ponsold A (1961) Erstickung. Dtsche Z Med 51:333-343
Redpath SA, van der Werf N, Cervera AM, Macdonald AS, Gray D, Maizels RM, Taylor MD (2013) ICOS controls Foxp3(+) regulatory T-cell expansion, maintenance and IL-10 production during helminth infection. Eur J Immunol 43:705-715

Shimada A, Iwata K, Morita T, Umemura T, Yamaga Y, Kagota K (1998) Biliary cirrhosis secondary to obstruction of the common bile duct by ectopic pancreas in a cow. J Comp Pathol 118:65-68

Somchit N, Norshahida AR, Hasiah A, Zuraini M, Sulaiman M, Noordin M (2004) Hepatotoxicity induced by antifungal drugs itraconazole and fluconazole in rats: a comparative in vivo study. Hum Exp Toxicol 23:519-525

Speranzini MB, Mittelstaedt W, Deutsch C, Cunha JC, Waisberg J (1988) Treatment of cicatricial stenosis of the proximal common hepatic duct. Study of 11 cases. Arq Gastroenterol 25:122-137

Sweeney JC, Ridgway SH (1975) Common diseases of small cetaceans. J Am Vet Med Assoc 167:533-540

Turner JD, Jenkins GR, Hogg KG, Aynsley SA and others (2011) CD4+CD25+ regulatory cells contribute to the regulation of colonic Th2 granulomatous pathology caused by schistosome infection. PLoS Negl Trop Dis 5: e1269

> Vítovec J (1974) Hepatocellular carcinoma in cattle and its relationship to biliary cirrhosis of fasciolar origin. Vet Pathol 11:548-557

Zam SG, Caldwell DK, Caldwell MC (1971) Some endoparasites from small odontocete cetaceans collected in Florida and Georgia. Cetology 2:1-11

Submitted: September 12, 2011; Accepted: June 13, 2013 Proofs received from author(s): August 28,2013
Editorial responsibility: Michael Moore,

Woods Hole, Massachusetts, USA 